without any difficulty across the ward. Nourishment was taken well. The first dressing was done under gas on June 1st, after which he complained of tinnitus in the right ear. Except for an attack of follicular tonsillitis he made an umeventful and uninterrupted recovery. He was able to walk downstairs ten days after the operation and left the hospital on June 30th. Marked rotatory nystagmus had been noted on June 4th; it was decidedly weaker on June 6th and was absent on June 17th. Before he left the hospital the patient began to hear the voice again with the right ear and functional testing on June 29th gave the following result: left ear, nil; right ear, voice three inches, Galton whistle $11048 \cdot 30$ vibrations. Bone conduction to all forks, nil. Air conduction, $3 \mathrm{C} 16$ and $2 \mathrm{C} 32=0,1 \mathrm{C} 64=$ ? perception, $\mathrm{C} 128=$ perception, $\mathrm{C}^{2} 256=-27$ seconds, $\mathrm{C}^{2} 512$ $=-38$ seconds, $\mathrm{C}^{3} 1024=-19$ seconds, $\mathrm{C}^{ \pm 2} 2048=-35$ seconds.

The patient spent the greater part of July at Deal and returned to me on July 28th. There was occasional slight buzzing on waking up, but no vertigo. His facial paralysis was improving. I last saw him on Sept. 2nd when over three months had elapsed since the operation. His condition then was as follows. The facial paralysis was much improved. $\mathrm{He}$ has occasional slight buzzing in the left ear on waking and after taking tea or coffee. This noise is not constant and nothing like the unbearable, machinery-like tinnitus from which he suffered before the operation. He has never had any vertigo or even slight giddiness since the operation. He stands firmly with the heels together and the eyes closed and has no nystagmus. By air conduction (right ear) he can hear all forks from $\mathrm{C}^{1}(256)$ to $\mathrm{C}^{\mathrm{s}}(2048)$ inclusive, but not those of lower pitch, but he still cannot hear any fork by bone conduction. He can converse well by lip-reading and can hear the ordinary voice by means of an ear-trumpet or when spoken close to the ear, and he can carry out his duties with ease and comfort.

The history of these operations on the labyrinth for the relief of vertigo or tinnitus incurable by other means and occurring in non-suppurative cases has already been given in the paper by Lake, already referred to. To recapitulate briefly the instances in which such operations have been performed, the first was that of Milligan, ${ }^{3}$ the second that of Lake, ${ }^{4}$ who, however, antedated Milligan in publication. The third case, also reported by Lake, was, I believe, the first in which the cochlea was attacked. Four more operations of the kind have been performed by Lake with success. I have been told of one unpublished and unsuccessful case performed in London by another surgeon, so that the one here reported is the ninth operation which has been undertaken. It has been, as the reader will have gathered, in every way successful. The method which I adopted-viz:, simple opening of the cochlea, vestibule, and canals, with the destruction of the ampullary soft parts-proved quite sufficient and was unaccompanied by the severe constitutional disturbance recorded by Lake in his first cases in which he removed one or more canals only. In my opinion the attacking of the labyrinth $v \hat{a}$ the radical mastoid operation is more scientific and certainly more justifiable (and less dangerous) than attempting to divide the auditory nerve in the skull, and this opinion I expressed at the Glasgow meeting of the Otological Society in 1904.

Harley-street, $W$.

\section{TWO CASES OF PNEUMOTHORAX.}

\section{BY J. PENN MILTON, M.R.C.S. ENG., L.R.C.P. LOND.}

CASE 1.-The patient, a male, aged 20 years, was admitted to the Udal Torre Sanatorium, Yelverton, on July 22nd, 1907, with a history of hæmoptysis off and on since March 1st. He was very pale and anæmic and had lost weight. Consolidation and crepitations were present on the right side from the apex to the fifth rib. There was a fair amount of expectoration. The temperature was above the normal, but it gradually settled down to normal. The patient was putting on weight and the lungs were clearing

3 Journal of the British Laryngological, Rhinological, and Otological Association, August, 1904

${ }_{4}$ THE LANCEN, June 4th, 1904, p. 1567.
5 Transactions of the Otological Society, vol. v., p. 67. up. On Sept. 22nd the temperature rose to $102 \circ \mathrm{F}$. after a short walk, and the patient went to bed. On Oct. Find a slight hremoptysis took place. On Nov. 8th as the temperature had been normal for several days it was arranged for him to get out of doors on the following day. At 5 A.M., however, the nurse found him with acute pain in the right chest, suffering from collapse with hurried respirations. Morphine was given. No physical signs could be heard to indicate the cause, but pneumothorax was suspected and it was easily diagnosable on the next day. Dyspncea and pain became so urgent owing to accumulation of air in the right pleural cavity that I inserted a cannula in the fifth intercostal interspace and immediate relief followed. A yellowish clear serous fluid escaped. On Nov. 13th I withdrew the cannula, but in a few hours the pain and dyspnœa were just as bad. Re-insertion of the cannula again gave relief. On Nov. 14th I removed the patient to the Charlton Nursing Home at Plymouth to be under the care of a surgeon (Mr. C. Hamilton Whiteford). During the journey the cannula came out. On arrival at the home the patient's condition was so good that the cannula was not re-inserted. From this time forward absolutely uninterrupted recovery was made and the patient returned to the sanatorium on Dec. 20th. From this date to last March, when the patient left, the temperature had been practically normal. The gain in weight since the attack had been 153 pounds. The right lung, which was collapsed, had made some progress towards expansion and a fair amount of exercise could be taken. The general condition was good and the disease apparentiy was arrested.

CASE 2.-The patient, aged 35 years, was admitted to the sanatorium on August 31st, 1907. On arrival he looked ill and his colour was unhealthy and earthy. A hard cough with no expectoration was present. The temperature was slightly above the normal. Consolidation and crepitations were present at the right apex with harsh breathing and prolonged expiration at the left apex. Improvement was quick; the temperature became normal and the general condition became distinctly better. After making good progress the temperature rose, expectoration commenced, and the right apex began to break down. The patient was confined to bed and the temperature was neither amenable to drugs nor to serums. The mental condition gave cause for anxiety; it was such that $I$ advised a change and he was taken to the same nursing home as the last patient. Here progress was again marked with a great reduction in the temperature and an improvement in the spirits of the patient. But after about a fortnight the patient was found to be in a state of collapse at midnight. Dr. H. A. Lyth was hurriedly called in and he found the patient propped up in bed in great distress from acute dyspncea, cold and livid, the pulse being 150 , the respirations 57 , and the temperature subnormal. There was no pain. On examination on the next day there were lack of movement on the right side and recession of the intercostal spaces during inspiration. On auscultation over the hyper-resonant area amphoric breathing with loud bubbling râles could be heard. A perforated lung with pneumothorax, which was shut off from the lower half of the chest by adhesions, was diagnosed. After the initial shock was passed the temperature rose again and the disease continued its active course as before, the patient dying on the fourteenth day from cardiac syncope. A postmortem examination made by Dr. Lyth showed the right lung to be universally adherent, the apex having to be torn away. The lower half, including the diaphragmatic adhesions which were recent, was easily separated. A localised pneumothorax was found over the adjacent parts of the upper and middle lobes. The perforation of a large cavity in the upper lobe showed as a freely open round hole a quarter of an inch in diameter. No fluid was present. There were tubercles in the upper and lower lobes of the left lung.

The two cases compared are interesting from the fact that pneumothorax was present in both cases in practically the same spot. Pain was present in one case and absent in the other. One patient died, the other recovered. The interesting point is whether the insertion of a cannula into the pleural cavity of the one case which recovered, causing a complete collapse of the lung and arrest of the disease, would have been equally successful in the case of the patient who died. Personally, in all future cases of pneumothorax I should feel very strongly inclined to insert a cannula into the 
affected side, so as to establish communication with the external air, as I believe that an absolute collapse of the lung, which was not primarily present in either of my cases but which connexion with the external air by means of the cannula induced in Case 1, is productive of good.

Yelverton.

\section{THE PREVENTION OF DEATHS UNDER AN ESTHETICS. ${ }^{1}$}

BY FREDERIO W. HEWITT, M.V.O., M.A., M.D. Cantab.,

ANASTHETIST TO H.M. THE KING ; PHYSICIAN-ANASTHETIST TO ST. GEORGE'S HOSPITAL; CONSULTING ANASTHETIST AND EMERITUS IECTURER ON AN ESTHETICS AT THE LONDON HOSPITAL.

THE prevention of deaths during and after general anæsthesia constitutes one of the most pressing questions of the present day. As one of the objects of the British Association is "the removal of any disadvantages of a public kind which impede the progress of science," and as the author of the present paper is firmly convinced that the risks connected with anæsthetics would be very materially reduced by improving the conditions and circumstances under which they are now administered, it is hoped that the Association may help to solve this question by making some pronouncement in favour of the reforms herein suggested. Although we have no reliable statistics as to the death-rates under different anæsthetics, there is ample evidence, firstly, that a very large number of persons have died wholly or partly from the effects of these drugs; and, secondly (doubtless owing to the increasing number of surgical operations), that fatalities of this kind are increasing to an appalling extent.

In order that the risks incidental to generalised anæsthesia may be reduced it is obviously necessary in the first place carefully to consider the conditions and circumstances under which anæsthetics are now administered. At the present moment (1) the law permits any person whatsoever, whether he be medically qualified or not, to produce general anæesthesia for a surgical operation; (2) many of the examining bodies for medical qualifications permit their candidates to qualify without producing evidence of having received instruction in anæsthetics ; (3) the departments of anæsthetics at our general hospitals are in many instances imperfectly and inadequately equipped, both in personnel and in other respects, the result being that the true principles of safe anæsthetisation are often barely, if at all, appreciated either by the teachers themselves or by their pupils; (4) in both hospital and private practice anæsthetics are frequently intrusted, even in the most difficult cases, to comparatively inexperienced practitioners who from no fault of their own find themselves incapable of successfully carrying out their responsible duties; and (5) with a few exceptions our hospitals publish no records as to the number and kinds of anæsthetics annually administered, so that any returns of deaths under anxsthetics, such as those of the Registrar-General of Births, Deaths, and Marriages, are useless as indicating either the relative risks of anæsthetics or the effects of any reforms upon death-rates.

It is hardly necessary to point out that if the public is to be protected properly the administration of anæsthetics must be placed upon a very different basis from that which at present exists. Experience has conclusively shown that though powerful poisons anæsthetics may be safely administered provided that those who undertake their administration have been properly educated and trained and that the principles under which they work and the methods which they employ are based upon scientific data. It would be beyond the scope of the present paper to enter fully into the strictly medical and scientific aspects of the problem of death prevention. It is contended that before such aspects can be profitably discussed the ground must be cleared by raising the level of this department of practice and by recognising the all-important fact that it is only by equipping all medical practitioners with increased knowledge and by applying it in practice that deaths under anæsthetics may be prevented. At the same time one cannot on such an occasion as the present refrain from acknowledging the valuable contributions to the subject which have been

1 A paper read before the Physiological Section of the British Associa tion for the Advancement of Seience, on Sept. 3rd, 1908. made by Professor A. Waller and other eminent physiologists, not only at previous meetings of this Association but elsewhere. Whilst fully appreciating the importance of their work and the fact that by regulating the percentage composition of anæsthetic atmospheres accidents may certainly be reduced in frequency, I am of opinion that before such methods can be adopted by medical practitioners and properly applied medical students must receive a better and wider education in anæsthetics than at present. They must be made fully to understand, in particular, the importance of free and absolutely unobstructed respiration; and when once the standard of education has thus been raised the strictly scientific work of the physiologist will yield a fruitful harvest. It is submitted that there is no single principle the faithful observance of which will insure safety in every case in which an anæsthetic is given. When we consider the different types of our subjects, the different operations which have to be performed, the different degrees of anæsthesia which may be required, the influences which different postures may have upon the circulation and respiration, and other essentially practical points, the truth of this proposition will become apparent. I would submit that there are three main principles which must collectively be observed in order to secure safe anæsthetisation. These are: (1) the selection of appropriate anæsthetics according to the exigencies of particular cases; (2) the adjustment of the vapour percentage of the anæsthetic to meet the varying requirements of each case; and (3) the avoidance of the slightest obstruction to the free entry and exit of air throughout the administration. Many distinguished authorities pin their faith to the second of these three principles, maintaining that by the regulation of the percentage composition of anæsthetic atmospheres dangerous conditions may invariably be avoided. This view I find myself unable to accept. Were it practicable in the human subject to introduce anæsthetic gases and vapours below the glottis and thus to eliminate the various forms of obstructed breathing which so often complicate and render fatal the anæsthesia of surgical practice, the administration of chloroform and other agents might undoubtedly be made as safe in the operating theatre as Professor Waller has demonstrated it can be made in the physiological laboratory. But such a system is unfortunately inapplicable, and I submit that unless it can be demonstrated that there is just as free a lung ventilation when a 1 per cent. or 2 per cent. chloroform vapour is administered to human subjects through the nasooral channels as there is when a similar percentage mixture is administered to lower animals through tracheal cannulæ, it is illogical to argue from the latter to the former subject. It would be exceedingly interesting and of great importance in solving the main question if arrangements could be made whereby a small committee of physiologists might see for themselves the manner in which anæsthetic difficulties and dangers generally come about in surgical practice. I am of opinion that such a committee would soon realise the great differences which exist between naso-oral and tracheal anæsthetisation and the marked influence which the asphyxial factor incidental to human anæsthetisation has in modifying and complicating the usual phenomena of anæsthesia. In the meantime I would urge that unless the other two principles above mentioned be applied in conducting all administrations success cannot be invariably depended upon. I am inclined, indeed, to regard the third, or last-mentioned, principle as the most important of the three, for my whole clinical experience and the examination of the records of a large number of recent fatal cases (which by the kindness of Dr. F. J. Waldo and of Dr. L. Freyberger have been placed at my disposal) convince me that in the great majority of deaths under anæsthetics some obstruction to breathing above the trachea has been a powerful factor.

I contend that the above considerations point to the urgent necessity for higher education and skill amongst those to whom the important duty is intrusted of maintaining adequate anæsthesia for surgical operations. The first reform should be to make it a penal offence for anyone but a legally qualified medical practitioner to administer an anæsthetic. The second should be to improve and extend the anæsthetic departments of our hospitals by appointing experienced men of the highest professional and academic attainments to the various offices of such departments, so that all anæs. thetics shall be administered or supervised by such 